This item is the archived peer-reviewed author-version of:

\title{
Design and evaluation of a multifunctional plate sediment trap suitable for subaqueous and floodplain environments
}

\section{Reference:}

Schoelynck Jonas, Oosterlee Lotte, Struyf Eric, Maris Tom, Meire Patrick, Temmerman Stijn.- Design and evaluation of a multifunctional plate sediment trap suitable for subaqueous and floodplain environments

Ecohydrology - ISSN 1936-0584 - 8:2(2015), p. 286-293

Full text (Publishers DOI): http://dx.doi.org/doi:10.1002/eco.1507

To cite this reference: http://hdl.handle.net/10067/1251780151162165141 
1 Schoelynck ${ }^{1}$, J., Oosterlee ${ }^{1}$, L., De Groote ${ }^{2}$, T., Maris ${ }^{1}$, T., Struyf ${ }^{1}$, E., Meire ${ }^{1}$, P.,

2 Temmerman ${ }^{1}$, S., 2015. Design and evaluation of a multifunctional plate sediment trap

3 suitable for subaqueous and floodplain environments. Ecohydrology 8(2), 286-293.

4

$5{ }^{1}$ University of Antwerp, Department of Biology, Ecosystem Management Research Group,

6 Universiteitsplein 1C, B-2610 Wilrijk, Belgium.

$7 \quad{ }^{2}$ University of Antwerp, Department of Biology, Plant and Vegetation Ecology Research Group,

8 Universiteitsplein 1C, B-2610 Wilrijk, Belgium.

$9{ }^{3}$ VITO, Unit Environmental Modelling, Boeretang 200, B-2400 Mol, Belgium.

10

11

12 *Corresponding author:

13 Jonas Schoelynck

14 UA - Campus Drie Eiken

15 Ecosystem Management research group

16 Universiteitsplein 1

17 Building C, C1.20

18 B - 2610 Wilrijk, Belgium

19 jonas.schoelynck@ua.ac.be

20 Tel +32 32652252

$21 \quad \mathrm{Fax}+3232652271$

22

23 Keywords: Biogeomorphology, lowland river, tidal flat, tidal marsh, macrophytes, plant-flow

24 interaction, sediment 


\section{Abstract}

26 In recent years it has become increasingly clear that two-way interactions between organisms

27 and landscape-forming processes play a key role in the evolution of many aquatic ecosystems.

28 To be able to compare sedimentation processes among different environments, a standardised

29 method that is generally applicable is necessary. Current methods are usually designed for one

30 environment only, or are unreliable in the presence of vegetation. This paper presents the

31 functionality of a plate sediment trap with a lid in combination with a filter paper, which enables

32 the measurement of sedimentation rates in both permanently subaqueous environments and

33 periodically flooded wetlands. We first present the trap design and demonstrate its functionality.

34 No significant differences were found between replicates, nor was there any indication of a trap

35 size effect on the sedimentation rate. Secondly, we demonstrate its applicability in periodically

36 flooded and permanently subaqueous environments, and in the presence or absence of

37 vegetation. It is concluded that the use of a standardized method and equipment makes it possible

38 to compare (bio)geomorphological changes in totally different environments. 


\section{$\underline{\text { Introduction }}$}

41 In recent years it has become increasingly clear that two-way interactions between organisms

42 and landscape-forming processes, also called biogeomorphological feedbacks, play a key role in

43 the evolution of many aquatic landscapes, such as floodplains and subaqueous environments

44 ((Bouma et al., 2013) and references therein). For example, (i) Larsen and Harvey (2010)

45 explained the stability of different landscape patterns in the Everglades by coupling vegetation

46 dynamics to both sediment transport and flow; (ii) a study by Temmerman et al. (2012)

47 demonstrates that large-scale vegetation die-off on tidal floodplains does not only result in

48 decreased platform sedimentation rates, but also in sediment infilling of the channels; and (iii)

49 Schoelynck et al. (2012) showed that the patchy vegetation pattern of Callitriche platycarpa

50 Kutz. in lowland rivers can be explained by scale-dependent feedbacks resulting patterns of

51 sedimentation and erosion, which stimulates or restricts patch growth. The difficulty in studying

52 the plant-flow-sediment interactions under natural conditions is compounded by the fact that

53 plants often form patches together with non-colonised spaces or spaces colonised by different

54 types of vegetation (Sukhodolov and Sukhodolova, 2010). This has led to insufficiently detailed

55 data sets for rigorous examination of plant-flow interactions relevant for natural conditions

56 (Sukhodolov and Sukhodolova, 2010). An important missing instrument in this context is a

57 standardised method to measure and compare sedimentation processes among different

58 environments and in different vegetation types (e.g. emergent vs. submerged). Most sediment

59 traps are designed for one environment only, or are unreliable in the presence of vegetation

60 (Banas and Masson, 2003).

61

62 
64 Sediment traps are relatively simple instruments which are commonly used for environmental

65 monitoring of the quantity and quality of sediment depositions in permanently or periodically

66 subaqueous environments. Sediment is collected over a limited period of time, measuring net

67 sediment accumulation over short periods (order of hours to months) rather than long-term

68 elevation change. A wide range of different designs of sediment traps have been used to quantify

69 sedimentation rates or downward sediment fluxes (Thomas and Ridd, 2004). Plates or tiles are

70 often applied in rivers (Gust and Kozerski, 2000; Kozerski, 2002), tidal wetlands (Keizer et al.,

71 1989; Pasternack and Brush, 1998; Temmerman et al., 2003), riparian wetlands and floodplains

72 (Steiger et al., 2003). Differently shaped cylinders, funnels, or containers are often used to study

73 settlement of sediment in a wide range of subaqueous environments (Bloesch and Burns, 1980).

74 However, plate sediment traps are preferred over cylindrical traps in rivers and dynamic

75 subaqueous environments in general (Kozerski and Leuschner, 1999).

76

77 Until the end of the 1970s, there was little consensus concerning the design requirements of this

78 equipment and the validity of sediment trap data (Bloesch and Burns, 1980). Then, crucial

79 laboratory and field investigations, primarily by Gardner (1980), later by Butman (1986) and

80 critical reviews (among others (Bloesch and Burns, 1980)) significantly improved the

81 understanding of sediment trap design and data collection. Cylindrical traps are known to

82 perform well in still waters, but have a tendency to overestimate sedimentation rates in more

83 hydrodynamic environments, because the reduction of turbulence and bottom shear stress within

84 the traps causes higher rates of sedimentation (Gust et al., 1996; Gust and Kozerski, 2000; 
85 Kozerski, 1994). Shear stress in flowing waters is an important controlling factor on

86 sedimentation, and should not be affected by the sediment trap design.

87 Flat devices have been used for sediment trapping in riparian or tidal wetlands (for an overview,

88 see (Steiger et al., 2003)). Examples include plain plywood boards (Braskerud, 2001;

89 Mansikkaniemi, 1985) or plain hardboard (Gretener and Stromquist, 1987), quasi-flat fire clay

90 roof tiles (Brunet et al., 1994), roughened plastic (Kleiss, 1996) or ceramic tiles (Pasternack and

91 Brush, 1998) anchored with a steel rod, sheets of plastic (Dezzeo et al., 2000), petri dishes

92 (Meeker, 1996), nylon carpet squares stitched to aluminium frames (Walker, 1995), or artificial

93 turf (Jeffiries et al., 2003). Still, one of the major technical problems of plate sediment traps is

94 the loss of material during retrieval (Gardner, 1980). In intertidal flats, marshes, or fluvial

95 floodplains the traps can be removed after inundation, but in permanently subaqueous

96 environments the trap should be covered with a lid before retrieval.

97 The first plate sediment trap described in literature that makes use of a lid is the bottom sediment

98 trap of Hakanson (1976), used in deep lakes. The trap consists of a big roughened Plexiglas

99 bottom plate with a raised edge of $0.05 \mathrm{~m}$, and in the centre a brass tube, to which a lid is

100 attached. The lid prevents material loss during the retrieval of the trap, yet also vertical settling

101 of suspended sediment is restrained by the lid. The same problem was still present with Kozerski

102 and Leuschner (1999), who proposed a plate sediment trap to determine sedimentation rates in

103 flowing waters. In collecting position, the cover still forms a roof above the collecting area and

104 vertically-settling particles are not collected. This may cause an underestimation of total

105 sedimentation rates, and the trap can definitely not be used in lentic systems (Banas and Masson,

106 2003). A solution for lentic systems came from Banas \& Masson (2003), who designed a plate

107 sediment trap with a bag system. During sediment collecting configuration, the polyethylene bag 
108 is folded under the collecting area. The bag is unfolded during trap retrieval by pulling threads,

109 preventing settled sediment to escape from the trap.

\section{Filter paper method}

112 Sediment deposition in floodplain environments is mostly measured by using the filter paper

113 method of Reed (1989): sampling the deposited sediment on pre-weighed filter paper, which is

114 secured to plastic discs and laid down on the marsh surface. After collection, the filter paper is

115 dried and reweighed to determine the weight of the deposited sediment. This is a very accurate

116 method, also in case of very slow sedimentation rates (Reed, 1989). Slight changes were

117 introduced to this method: (i) the type of filter paper: glass fibre (Culberson et al., 2004;

118 Davidson-Arnott et al., 2002; French et al., 1995), ashless filter paper (French and Spencer, 119 1993); (ii) the disc itself: petri dish lid with slot (Davidson-Arnott et al., 2002), petri dish varying 120 from rim up- or downwards (Culberson et al., 2004; French and Spencer, 1993; French et al., 121 1995), aluminium plate (Temmerman et al., 2005), plastic plate (Temmerman et al., 2003), metal 122 plate (Allen and Duffy, 1998); (iii) fixation of the trap to the soil: metal pins (French and 123 Spencer, 1993; French et al., 1995), steel claws (Temmerman et al., 2003); and (iv) fixation of 124 filter to the trap: plastic coated pins (Davidson-Arnott et al., 2002), wire staples (Culberson et 125 al., 2004).

126

127 All traps described so far are either specifically designed for floodplain environments or tidal 128 marshes (i.e. periodically subaqueous) or for permanent subaqueous environments. The first 129 category often uses filter paper and the use of a lid is not necessary (because of the periodically 130 dry periods). In the second category, the use of filter paper is not common, and the use of a lid is 
131 inevitable for retrieving the trap with the sediment. To be able to compare sedimentation

132 processes among different environments, a standardised method that is applicable everywhere is 133 necessary. Based on the proven and established features of previously described traps, we 134 designed and tested a plate sediment trap with a lid in combination with the filter paper method. 135 This method enables the measurement of sedimentation rates on vegetated and non-vegetated 136 soils in both permanently subaqueous environments and periodically flooded wetlands. We first 137 present the trap design and demonstrate its functionality by evaluating the reproducibility and the 138 effect of different trap sizes. Secondly, we demonstrate its applicability in three different 139 ecosystems: (i) two tidal flats, (ii) a tidal marsh, and (iii) a lowland river, all three characterised 140 by different hydrodynamic conditions and diverse vegetation cover. Due to the use of a special 141 lid system, no loss of material occurs during retrieval. 


\section{$143 \quad$ Materials and methods}

\section{Construction}

145 The sediment trap (figure 1; movie 1) is a circular PVC plate of any size with a groove of 1-2 $146 \mathrm{~mm}$ deep, which is carved at the edge of the bottom of the plate. A small hole $(\varnothing=5 \mathrm{~mm})$ is 147 drilled through the middle of the plate and three more screw thread holes are drilled on the 148 outside. On the top of the trap, a circle is carved out leaving a rim of 1-2 $\mathrm{mm}$ high and 1-2 $\mathrm{cm}$ 149 wide. The inside of the rim has a bevelled edge. In this inner circle, a cellulose filter is attached 150 by pressing it between the plate and a PVC ring that fits the inner circle exactly. In this way 151 water is prevented from flowing under the filter. The ring, which is a little bit larger in diameter

$152(1 \mathrm{~mm})$ than the inner circle, has a conversely bevelled edge and from this ring $1 \mathrm{~cm}$ is removed, 153 making it incomplete so that its diameter can be slightly adjusted by the flexibility of the PVC. 154 This construction allows the ring to slot into the rim of the trap. The cellulose filter has a pore 155 size of $2.7 \mu \mathrm{m}$ (supporting its strength when it is wet) and is circular, with a diameter equal to 156 that of the inner circle of the trap. The filter is capable of withstanding wetting and drying 157 without loss of weight (e.g.: Whatman 50 Cellulose Filters, hardened low ash, Whatman 158 International Ltd., Maidstone, England). The circular part of the filter enclosed by the PVC ring 159 is the actual area on which sedimentation will be measured. The lid is constructed from part of a 160 PVC tube and a circular PVC plate, both of equal diameter to that of the trap itself. A small hole $161(\varnothing=5 \mathrm{~mm})$ is drilled into the centre of the lid. The upright edge is covered with a flexible rubber 162 ribbon making the lid water- and airtight when attached to the trap. On the outside of the lid, 163 three clamps are attached that can hook into the carved groove on the bottom of the trap. 


\section{Operation}

167 Filters are pre-weighed in the lab after drying at $105{ }^{\circ} \mathrm{C}$ to constant mass. The filters are then

168 pinched into the traps. The traps are fixed to the soil surface at a measuring site by screwing

169 three metal pins into the screw thread holes underneath the trap and pushing them all the way

170 into the sediment. On floodplains, this is best done during low water, when the wetlands are not

171 flooded. When the water level rises, the sediment traps become flooded and the sediment

172 particles can settle out of suspension. The filters with sediment are collected during subsequent

173 low water, dried and weighed in the laboratory to determine the amount of sediment deposited

174 during one inundation event. In subaqueous environments where the bottom can be reached by

175 hand, the traps can easily be placed under water manually. In deeper parts the operator has to

176 dive, which can be a limiting factor, yet not different from other devices applied in deep water

177 ((Bloesch and Burns, 1980) and references therein). Sedimentation occurs immediately after

178 installation and particles settle partially from bed transport as well as from suspension. The 179 duration of time for which the traps collect sediments is used for calculating the sedimentation 180 rate.

181 Trap retrieval is easy in periodically flooded environments as these sites are dry during periods

182 of low water. Using the lid is not necessary, yet is recommended to prevent contamination or loss

183 of material during transport. For retrieving the traps in subaqueous environments the traps are 184 best approached from downstream, preventing extra sedimentation or erosion from the operators' 185 movements. The hole in the lid needs to be covered with waterproof tape and the lid should be 186 moved gently in the water towards the trap. Under the water the clamps are attached into the 187 groove and the trap can be removed safely. The tape will prevent water leaking out of the trap by 188 creating a vacuum under the lid. Once transported to the lab removing the tape allows the water 
189 to leak out slowly through the filter and through the hole at the bottom side of the trap. Once it

190 stops leaking, the lid can be removed and the filter with the sediment becomes accessible.

191 Filters are removed by removing the PVC ring. Filter and sediment are dried together at a $105^{\circ} \mathrm{C}$

192 until a constant mass is reached. Sedimentation rates are calculated with equation (1):

$$
\frac{\text { mass }_{\text {filter }+ \text { sediment }}-\text { mass }_{\text {filter }}}{\text { surface }_{\text {trap }} * \text { time }} \quad\left(\text { in } \frac{g}{m^{2} s}\right)(1)
$$

194 Afterwards, dry sandy sediment can easily be wiped from the filter using a small brush, yet 195 fractions with a small grain size (clay) may stick to the filter pores. Note that if chemical 196 analyses on the sediment are required, it may be necessary to dry it at different temperatures.

198 Evaluating the functionality of the trap

199 The functionality of the trap was tested for two parameters: reproducibility and trap size

200 influence. This was done in three different ecosystems (figure 2): (i) two tidal flats with different 201 tidal regimes (i.e. a non-vegetated periodically flooded environment), (ii) a tidal marsh adjacent 202 to one of the studied flats (with vegetation), and (iii) a lowland river (i.e. permanently 203 subaqueous environment) dominated by patchy submerged vegetation, interspersed with non204 vegetated zones.

205 The first tidal flat-tidal marsh system is part of an experimental area ("Lippenbroek"; 8.2 ha) in 206 the freshwater zone of the Scheldt estuary, Belgium. In this area a controlled reduced tide system 207 (CRT) was created (Beauchard et al., 2011; Maris et al., 2007; Vandenbruwaene et al., 2011). 208 Managed realignment would have resulted in complete flooding due to the initially low elevation 209 of the area; an adapted sluice system now regulates the tide in a way that the area is exposed to 210 almost natural tidal flooding, including the spring-neap cycle of approximately $3 \mathrm{~m}$, which 211 allows the development a range of estuarine habitats from mudflat to tidal marsh. The major 
212 difference compared to a natural system is a prolonged flooding duration of app. three hours.

213 Vegetation consists of pioneer freshwater marsh species, such as water pepper (Persicaria

214 hydropiper), purple loosestrife (Lythrum salicaria), several helophytes, such as common reed

215 (Phragmites australis), common bulrush (Typha latifolia), saltmarsh bulrush (Bolboschoenus

216 maritimus) and willow forest (Salix sp.). Vegetation cover differs with season and elevation

217 between 0 and $100 \%$. In highly productive areas, reed densities differ between $1500-3000 \mathrm{~g} \mathrm{~m}^{-}$

$218{ }^{2}$, reed canary grass (Phalaris arundinacea) between $100-1000 \mathrm{~g} \mathrm{~m}^{-2}$. The second tidal flat is

219 part of another nature restoration area for intertidal habitats ("Burchtse Weel"; 14.4 ha) located

220 in the brackish water zone of the Scheldt estuary. This area is exposed to the complete estuarine

221 tidal cycle of app. $5 \mathrm{~m}$ and has currently no vegetation cover. Sediments in both tidal areas are

222 silty $(\mathrm{D} 50=14 \mu \mathrm{m})$ and current velocities at both sites are typically not more than a few $\mathrm{cm} \mathrm{s}^{-1}$

223 (e.g. (Temmerman et al., 2012)). The Zwarte Nete is a typical lowland river in the NE of

224 Belgium dominated by submerged patchy vegetation (40\% coverage and biomass may reach 0.5

$225 \mathrm{~kg} \mathrm{DM} \mathrm{m}^{-2}$ ). The river has an average width of $4.5 \mathrm{~m}$ (max. $6.2 \mathrm{~m}$ ). The river bed consists of

226 sandy sediments $(\mathrm{D} 50=167 \mu \mathrm{m})$ and water flows with an average stream velocity around $0.1 \mathrm{~m}$

$227 \mathrm{~s}^{-1}$ and an average discharge of $0.2 \mathrm{~m}^{3} \mathrm{~s}^{-1}$ in summer. Water depth rarely exceeds $1 \mathrm{~m}$ and water 228 surface slope is on average $0.0012 \mathrm{~m} \mathrm{~m}^{-1}$ (for more details on the study area see e.g. Schoelynck 229 et al. 2012).

230

231 In the first test for reproducibility, twelve pairs of identical sediment traps were positioned in the

232 Zwarte Nete river (six pairs in non-vegetated zones and six pairs in patches of different

233 submerged and emergent species) and in Lippenbroek (six pairs on the tidal flat (bare sediment),

234 and six pairs in the vegetation of different emergent species). Each member of a pair was treated 
235 as a replicate, and a few meters distance was kept between each pair to minimise possible 236 interference. Diameters of the traps were $0.10 \mathrm{~m}$ in the river and $0.20 \mathrm{~m}$ on the tidal flats/marsh.

237 The bathymetry of the Zwarte Nete was more variable than those of the tidal flats/marsh. We 238 therefore used smaller trap sizes in the river so that each pair of traps could be placed 239 horizontally next to each other. Secondly, to test possible trap size effects, five pairs of a large $(\varnothing$ $240=0.20 \mathrm{~m})$ and a small $(\varnothing=0.10 \mathrm{~m})$ sediment trap were placed two-by-two randomly on non241 vegetated soil in each of the three test sites (only four pairs in Lippenbroek). This test was 242 repeated on vegetated soils with six pairs in the river and six pairs in Lippenbroek. All 243 experiments lasted for five days (Zwarte Nete) or for app. twelve hours (one tidal cycle). After 244 retrieval the samples were dried for $48 \mathrm{~h}$ at $105^{\circ} \mathrm{C}$. Statistical analyses were performed with 245 SAS 9.2 (SAS Institute inc., Cary, USA). We used a paired t-test to compare results from 246 identical traps in each pair and a Pearson correlation test to test the relationship between results 247 obtained by traps of different sizes. 


\section{$249 \underline{\text { Results }}$}

250 No significant difference in reproducibility between traps of the same pair in both habitats was

251 found (paired t-test, $\mathrm{p}=0.65$ for non-vegetated soil, $\mathrm{p}=0.35$ for vegetated soil; table 1 ). To

252 evaluate the effect of trap size, sedimentation rates measured on the small traps were plotted

253 against the sedimentation rates measured in the large traps (in $\mathrm{g} \mathrm{m}^{-2}$ day $^{-1}$, figures $3 \mathrm{a}, \mathrm{b}$ ). We

254 found that sedimentation rates on non-vegetated soils are one order of magnitude higher than

255 those inside vegetation. The results obtained for non-vegetated soil with a large trap and with a

256 small trap are significantly correlated (Pearson correlation test, $\mathrm{p}<0.0001, \mathrm{R}^{2}=0.94$ ). The slope of

257 the regression line (0.97) is close to 1 , and the intercept is 0 . The results obtained on a vegetated

258 soil with a large trap and with a small trap are also significantly correlated (Pearson correlation

259 test, $\left.\mathrm{p}<0.0001, \mathrm{R}^{2}=0.93\right)$. Similarly, the slope of the regression line (1.05) is close to 1 , and the

260 intercept 0 . There are no significant differences between sedimentation rates measured in the

261 small and large traps of the same pair in all three study areas (paired t-test, $\mathrm{p}=0.94$ for non-

262 vegetated soil, $\mathrm{p}=0.80$ for vegetated soil). 


\section{Discussion}

265 Classic plate sediment traps are known to accurately measure sedimentation in dynamic systems,

266 because they limit the reduction of turbulence and bottom shear stress in comparison to

267 cylindrical traps with a high rim (Gust and Kozerski, 2000; Kozerski, 2002). However in most

268 studies the design of the trap was (slightly) different to suit the variety of environments the trap

269 was deployed in. This made it difficult to compare results from different ecosystems. This paper

270 showed that the same plate sediment traps in combination with filter paper and a lid can be used

271 in various ecosystems. It renders robust reproducible estimations of sedimentation rates that can

272 be compared among the different aquatic habitats. The design of the trap has many advantages:

273 (i) it is robust and can therefore withstand repeated flooding and laboratory processing; (ii) it can

274 be securely attached to the soil surface with metal pins thereby resisting relatively high stream

275 velocities and associated shear stresses (tested up to $0.4 \mathrm{~m} \mathrm{~s}^{-1}$, personal experience); (iii) it is

276 light and easily manipulated in the field; (iv) a lid can be placed on the trap before retrieval,

277 avoiding the loss of material during or after retrieval; and (v) the use of the filter paper allows for

278 full recovery of all deposited sediment, which is especially important for measuring small

279 amounts of sediment and it allows sampling of the trapped material for chemical or physical

280 analyses. Trap construction is relatively easy and inexpensive. The average time for our

281 university technicians to construct one trap is about 30 minutes. The material cost per trap is app.

28250 Euros, although actual costs will vary per country. Only commercially available materials and

283 techniques were used.

285 The trap was shown to work effectively in lowland rivers, as an example of a permanently 286 subaqueous environment, as well as on tidal flats and tidal marshes, as an example of 
287 periodically flooded environments. Moreover these traps have been successfully used in different

288 vegetation types: submerged, emergent, and shrubs and trees (Figure 4). The application in 289 different habitats and environments gives an unmistakable advantage. Geomorphological 290 changes can now be compared between different ecosystems in a reliable way. In fact, in 291 periodically flooded environments the use of cylindrical traps with a rim is not possible: traps 292 must be able to drain during low water while retaining sediment deposited on them. Our 293 experiments showed that there is no influence of trap size, indicating minimal 'edge' effects. 294 This is in accordance with French and Spencer (1993), who performed experiments with 3 295 different trap diameters $(\varnothing=0.05,0.09$ and $0.11 \mathrm{~m})$, revealing no significant variation in 296 sedimentation per trap. Small traps may be used when areas have irregular surfaces. 297 Microtopography of the surface may influence sedimentation, and this effect is absent on flat 298 filter paper. Nevertheless, the small trap size allows it to be placed on horizontal parts of the 299 surface where such influences are negligible. Small traps are also better to use in vegetation 300 stands (in permanently subaqueous environments, as well as periodically flooded areas). They fit 301 better in between individual stems whereas larger traps may crush and cover part of the 302 vegetation which can influence sedimentation. The fact that the same small plate traps can now 303 be used in vegetation of different environments makes it possible to measure the effect of 304 vegetation on geomorphological processes, or to compare the effects of vegetation on 305 geomorphology in different ecosystems, or of plants with different traits and growth forms. Trap 306 size can be adjusted to field characteristics: e.g.: larger traps may be more suitable in non307 vegetated, flat areas with very few transported particles. 
311 The robustness and easy handling of the trap makes it suitable in many situations, as was

312 discussed previously. However based on our personal experience, there are circumstances under

313 which special attention is needed. In tidal habitats the investigated period of time may comprise

314 several tides and the weather during low tides may influence the result. On sunny days, sediment

315 can dry out on the filter paper more than on the flat/marsh itself. Obtained sedimentation rates

316 are always net results of sedimentation and resuspension, but it is likely that dried sediment will

317 adhere to the paper surface (Reed, 1989) and may not resuspend during the next flooding. This

318 may result in an overestimation for tidal flats, although resuspension of deposited sediments on

319 marshes is very rare because of the typically low flow velocities and bed shear stress values

320 within marsh vegetation (Christiansen et al., 2000). Rain events during low tide or before

321 collection may cause sediment erosion which can result in an underestimation. This can be

322 prevented with a floatable cover to protect the deposited sediment from splashing by raindrops

323 during low tides (Temmerman et al., 2003), but this is technically more challenging. In

324 subaqueous environments too much aquatic vegetation can make it complicated to find traps.

325 Attaching small floaters with nylon wire to the iron rods of the trap can help without influencing

326 the current and the resulting sedimentation. It is also important to acknowledge the potential

327 additive effect of suspended material caught underneath the lid when moving it towards the trap

328 in subaqueous environments. This effect could cause an overestimation when the actual

329 sedimentation is very small. It can be corrected by subtracting this amount (i.e. suspended solids

330 concentration of the environment (g per volume) times the volume of the lid) from the total

331 amount on the filter. Finally in general, the use of sticks close to the trap as a marker is not 
332 recommended in any situation as it may influence the result, traps cannot be used on slopes and

333 their use is seriously restricted in deep or fast flowing water.

335 In conclusion, we presented an integrated version of a classical plate sediment trap in 336 combination with a lid and a filter paper. Several tests showed that the trap gives good

337 reproducible estimations of sedimentation rates in various ecosystems. There is no size effect of 338 the trap which makes it possible to fit any desired space or location, vegetated or not. The use of 339 a standardized method and equipment makes a comparison of (bio)geomorphological changes in 340 different environments and in various vegetation types possible.

\section{Acknowledgements}

343 The authors like to thank the technical staff of the Antwerp University for building the traps. We 344 also thank Waterways and Sea Canal (W\&Z) for financing the monitoring projects along the 345 Scheldt and BELSPO for funding project SOGLO. T.D.G. is a Ph.D. fellow of the Research 346 Foundation - Flanders (FWO) and the Flemish Institute for Technological Research (VITO). The 347 authors acknowledge Amon Kimeli for the mangroves picture, Johnny Teuchies for the tidal 348 marsh picture, Jens Verschaeren for help in the field, Kurt Kerkhofs for editing the movie and 349 Alanna Rebelo for proofreading this manuscript and being the narrator of the movie. The authors 350 have no conflict of interest to declare. 


\section{References}

353

Allen, J.R.L., Duffy, M.J., 1998. Temporal and spatial depositional patterns in the Severn Estuary, southwestern Britain: intertidal studies at spring-reap and seasonal scales, 1991-1993. Marine Geology 146, 147-171.

Banas, D., Masson, G., 2003. New plate sediment traps for lentic systems. Archiv Fur Hydrobiologie 158, 283-288.

Beauchard, O., Jacobs, S., Cox, T.J.S., Maris, T., Vrebos, D., Van Braeckel, A., Meire, P., 2011. A new technique for tidal habitat restoration: Evaluation of its hydrological potentials. Ecological Engineering 37, 1849-1858.

Bloesch, J., Burns, N.M., 1980. A Critical-Review of Sedimentation Trap Technique. Schweizerische Zeitschrift Fur Hydrologie-Swiss Journal of Hydrology 42, 15-55.

Bouma, T.J., Temmerman, S., van Duren, L.A., Martini, E., Vandenbruwaene, W., Callaghan, D.P., Balke, T., Bierman, G., Klaassen, P.C., van Steeg, P., Dekker, F., van de Koppel, J., de Vries, M.B., Herman, P.M.J., 2013. Organism traits determine the strength of scale-dependent bio-geomorphic

feedbacks: A flume study on three intertidal plant species. Geomorphology 180-181, 57-65.

Braskerud, B.C., 2001. The influence of vegetation on sedimentation and resuspension of soil particles in small constructed wetlands. Journal of Environmental Quality 30, 1447-1457.

Brunet, R.C., Pinay, G., Gazelle, F., Roques, L., 1994. Role of the floodplain and riparian zon ein suspended matter and nutrogen-retention in the Adour river, south-west France. Regulated Rivers-Research \& Management 9, 55-63.

Butman, C.A., 1986. Sediment Trap Biases in Turbulent Flows - Results from a Laboratory Flume Study. Journal of Marine Research 44, 645-693.

Christiansen, T., Wiberg, P.L., Milligan, T.G., 2000. Flow and sediment transport on a tidal salt marsh surface. Estuarine Coastal and Shelf Science 50, 315-331.

Culberson, S.D., Foin, T.C., Collins, J.N., 2004. The role of sedimentation in estuarine marsh development within the San Francisco Estuary, California, USA. Journal of Coastal Research 20, 970-979.

Davidson-Arnott, R.G.D., van Proosdij, D., Ollerhead, J., Schostak, L., 2002. Hydrodynamics and sedimentation in salt marshes: examples from a macrotidal marsh, Bay of Fundy. Geomorphology 48, 209-231.

Dezzeo, N., Herrera, R., Escalante, G., Chacon, N., 2000. Deposition of sediments during a flood event on seasonally flooded forests of the lower Orinoco River and two of its black-water tributaries, Venezuela. Biogeochemistry 49, 241-257.

French, J.R., Spencer, T., 1993. Dynamics of Sedimentation in a Tide-Dominated Backbarrier Salt-Marsh, Norfolk, Uk. Marine Geology 110, 315-331.

French, J.R., Spencer, T., Murray, A.L., Arnold, N.S., 1995. Geostatistical Analysis of Sediment Deposition in 2 Small Tidal Wetlands, Norfolk, Uk. Journal of Coastal Research 11, 308-321. Gardner, W.D., 1980. Sediment trap dynamics and calibration - a laboratory evaluation. Journal of Marine Research 38, 17-39.

Gretener, B., Stromquist, L., 1987. Overbank sedimentation-rates of fine-grained sediments - a study of the recent deposition in the lower river Fyrisan. Geografiska Annaler Series a-Physical Geography 69, 139-146.

Gust, G., Bowles, W., Giordano, S., Huttel, M., 1996. Particle accumulation in a cylindrical sediment trap under laminar and turbulent steady flow: An experimental approach. Aquatic Sciences 58, 297-326. 
398

399

400

401

402

403

404

405

406

407

408

409

410

411

412

413

414

415

416

417

418

419

420

421

422

423

424

425

426

427

428

429

430

431

432

433

434

435

436

437

438

439

440

441

442

443

444

445

Gust, G., Kozerski, H.P., 2000. In situ sinking-particle flux from collection rates of cylindrical traps. Marine Ecology-Progress Series 208, 93-106.

Hakanson, L., 1976. Bottom sediment trap for recent sedimentary deposits. Limnology and Oceanography 21, 170-174.

Jeffiries, R., Darby, S.E., Sear, D.A., 2003. The influence of vegetation and organic debris on flood-plain sediment dynamics: case study of a low-order stream in the New Forest, England. Geomorphology 51, 61-80.

Keizer, P.D., Hargrave, B.T., Gordon, D.C., 1989. Sediment-Water Exchange of Dissolved Nutrients at an Intertidal Site in the Upper Reaches of the Bay of Fundy. Estuaries 12, 1-12.

Kimeli, A.K., 2013. Sedimentation in response to sea level rise in the mangroves of Mwache Creek, Mombasa-Kenya: a field and modeling study. Interuniversity master thesis in Marine and Lacustrine Science and Management, Antwerp.

Kleiss, B.A., 1996. Sediment retention in a bottomland hardwood wetland in Eastern Arkansas. Wetlands 16, 321-333.

Kozerski, H.P., 1994. Possibilities and limitations of sediment traps to measure sedimentation and resuspension. Hydrobiologia 284, 93-100.

Kozerski, H.P., 2002. Determination of areal sedimentation rates in rivers by using plate sediment trap measurements and flow velocity - settling flux relationship. Water Research 36, 2983-2990.

Kozerski, H.P., Leuschner, K., 1999. Plate sediment traps for slowly moving waters. Water Research 33, 2913-2922.

Larsen, L.G., Harvey, J.W., 2010. How Vegetation and Sediment Transport Feedbacks Drive Landscape Change in the Everglades and Wetlands Worldwide. American Naturalist 176, E66E79.

Mansikkaniemi, H., 1985. Sedimentation and water quality in the flood basin of the river Kyrönjoki in Finland. Fennia 163, 155-194.

Maris, T., Cox, T., Temmerman, S., De Vleeschauwer, P., Van Damme, S., De Mulder, T., Van den Bergh, E., Meire, P., 2007. Tuning the tide: creating ecological conditions for tidal marsh development in a flood control area. Hydrobiologia 588, 31-34.

Meeker, J.E., 1996. Wild-rice and sedimentation processes in a Lake Superior coastal wetland. Wetlands 16, 219-231.

Pasternack, G.B., Brush, G.S., 1998. Sedimentation cycles in a river-mouth tidal freshwater marsh. Estuaries 21, 407-415.

Reed, D.J., 1989. Patterns of sediment deposition in subsiding coastal salt marshes, Terrebonne Bay, Louisiana - The role of winter storms. Estuaries 12, 222-227.

Schoelynck, J., De Groote, T., Bal, K., Vandenbruwaene, W., Meire, P., Temmerman, S., 2012. Self-organised patchiness and scale-dependent bio-geomorphic feedbacks in aquatic river vegetation. Ecography 35, 760-768.

Steiger, J., Gurnell, A.M., Goodson, J.M., 2003. Quantifying and characterizing contemporary riparian sedimentation. River Research and Applications 19, 335-352.

Sukhodolov, A.N., Sukhodolova, T.A., 2010. Case Study: Effect of Submerged Aquatic Plants on Turbulence Structure in a Lowland River. Journal of Hydraulic Engineering-Asce 136, 434-446.

Temmerman, S., Bouma, T.J., Govers, G., Wang, Z.B., De Vries, M.B., Herman, P.M.J., 2005. Impact of vegetation on flow routing and sedimentation patterns: Three-dimensional modeling for a tidal marsh. Journal of Geophysical Research-Earth Surface 110, 18.

Temmerman, S., Govers, G., Wartel, S., Meire, P., 2003. Spatial and temporal factors controlling short-term sedimentation in a salt and freshwater tidal marsh, Scheldt estuary, Belgium, SW Netherlands. Earth Surface Processes and Landforms 28, 739-755. 
446 Temmerman, S., Moonen, P., Schoelynck, J., Govers, G., Bouma, T.J., 2012. Impact of 447 vegetation die-off on spatial flow patterns over a tidal marsh. Geophysical Research Letters 39.

448 Thomas, S., Ridd, P.V., 2004. Review of methods to measure short time scale sediment 449 accumulation. Marine Geology 207, 95-114.

450 Vandenbruwaene, W., Maris, T., Cox, T.J.S., Cahoon, D.R., Meire, P., Temmerman, S., 2011. 451 Sedimentation and response to sea-level rise of a restored marsh with reduced tidal exchange: 452 Comparison with a natural tidal marsh. Geomorphology 130, 115-126.

453 Walker, I., 1995. Sedimentation in the inundation forest flanking the Central Amazonian 454 blackwater stream Rio Taruma Mirim (Manaus, Amazonas State). Amazoniana-Limnologia Et 455 Oecologia Regionalis Systemae Fluminis Amazonas 13, 237-243. 
458 Table 1 Sedimentation rates of 12 pairs of replicate traps in two different environments: a 459 lowland river (Zwarte Nete) and a tidal flat/marsh (Lippenbroek). Both sites have non-vegetated 460 locations, as well as locations with various vegetation types: $(\mathrm{e})=$ emergent, $(\mathrm{s})=$ submerged, $(\mathrm{t})$ $461=$ tree/shrub.

462

\begin{tabular}{|c|c|c|c|c|c|c|}
\hline \multirow[b]{2}{*}{ Non } & \multicolumn{2}{|c|}{$\begin{array}{l}\text { Zwarte Nete } \\
\left(\text { g m}^{-2} \text { day }^{-1}\right)\end{array}$} & \multicolumn{4}{|c|}{$\begin{array}{l}\text { Lippenbroek } \\
\left(\mathrm{g} \mathrm{m}^{-2} \text { day }^{-1}\right)\end{array}$} \\
\hline & Plate 1 & Plate 2 & & Plate 1 & Plate 2 & \\
\hline vegetated & 606 & 531 & & 244 & 317 & \\
\hline \multirow[t]{5}{*}{ soil } & 256 & 155 & & 246 & 154 & \\
\hline & 420 & 640 & & 147 & 114 & \\
\hline & 480 & 527 & & 323 & 302 & \\
\hline & 376 & 222 & & 279 & 257 & \\
\hline & 143 & 127 & & 90 & 119 & \\
\hline & 102 & 79 & $\begin{array}{l}\text { Sparganium } \\
\text { emersum (s) }\end{array}$ & 15 & 40 & $\begin{array}{l}\text { Phalaris } \\
\text { arundinaceae } \\
\text { (e) }\end{array}$ \\
\hline & 178 & 138 & $\begin{array}{l}\text { Ranunculus } \\
\text { fluitans (s) }\end{array}$ & 25 & 30 & Salix sp. (t) \\
\hline & 87 & 222 & $\begin{array}{l}\text { Typha } \\
\text { latifolia (e) }\end{array}$ & 20 & 18 & $\begin{array}{l}\text { Phragmites } \\
\text { australis (e) }\end{array}$ \\
\hline & 13 & 25 & $\begin{array}{l}\text { Potamogeton } \\
\text { natans (s) }\end{array}$ & 9 & 6 & $\begin{array}{l}\text { Phragmites } \\
\text { australis (e) }\end{array}$ \\
\hline & 25 & 74 & $\begin{array}{l}\text { Potamogeton } \\
\text { natans }\end{array}$ & 8 & 6 & $\begin{array}{l}\text { Phragmites } \\
\text { australis (e) }\end{array}$ \\
\hline & 69 & 59 & $\begin{array}{l}\text { Potamogeton } \\
\text { natans (s) }\end{array}$ & 31 & 35 & $\begin{array}{l}\text { Phragmites } \\
\text { australis (e) }\end{array}$ \\
\hline
\end{tabular}




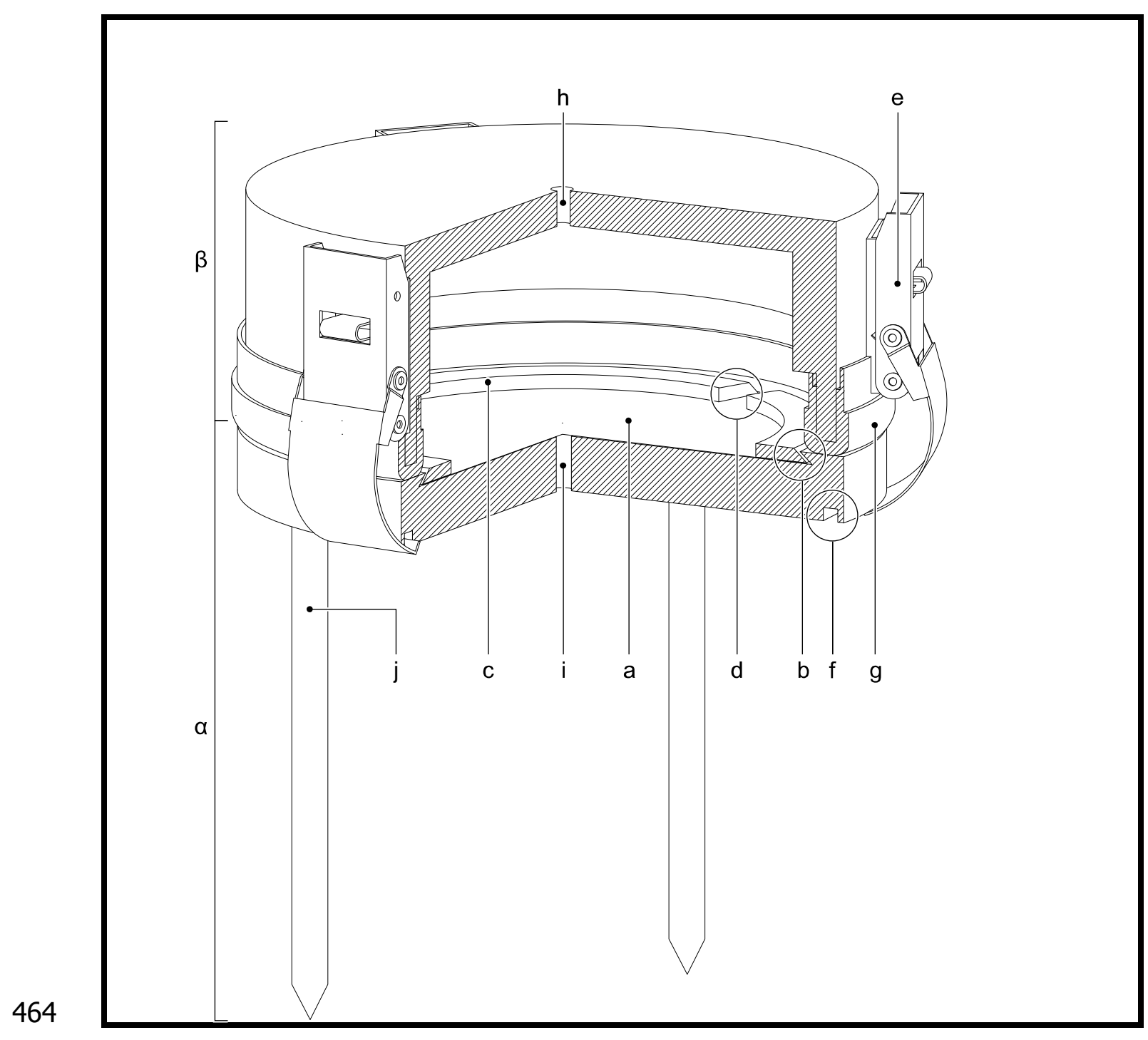

Figure 1

466 Schematic design of the plate sediment trap $(\alpha)$ and lid $(\beta)$ with the cellulose filter (a), carried by

467 the base plate of the trap and locked into place (b) by a PVC ring (c) with a small interruption

468 (d). The clamps (e) of the lid fit into the groove in the bottom of the trap (f), securing the lid to

469 the sediment trap. A flexible rubber ribbon on the rim of the lid ( $\mathrm{g}$ ) controls the pressure

470 (vacuum) inside the trap when the small hole in the lid (h) is covered with tape. The water inside

471 the trap is empties through a second small hole in the trap (i). The sediment trap is anchored onto

472 the soil surface with three metal pins (j). 


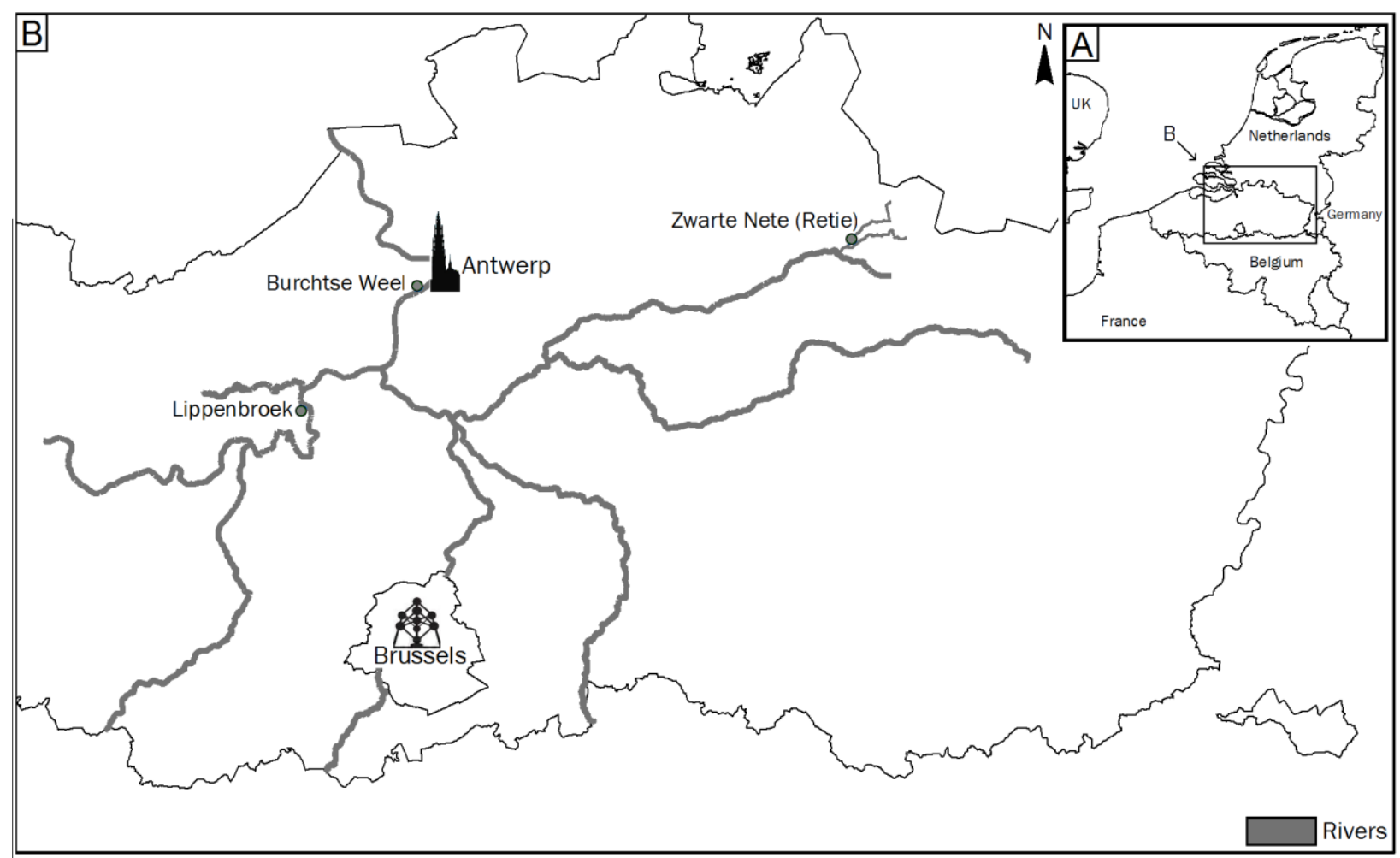

475 Figure 2

476 Map of the Northern part of Belgium with its main rivers draining towards the Belgian part of 477 the Scheldt estuary. Sample station Lippenbroek is a tidal flat/marsh system, station Burchtse 478 Weel is a tidal flat, and station Zwarte Nete is a lowland river. 

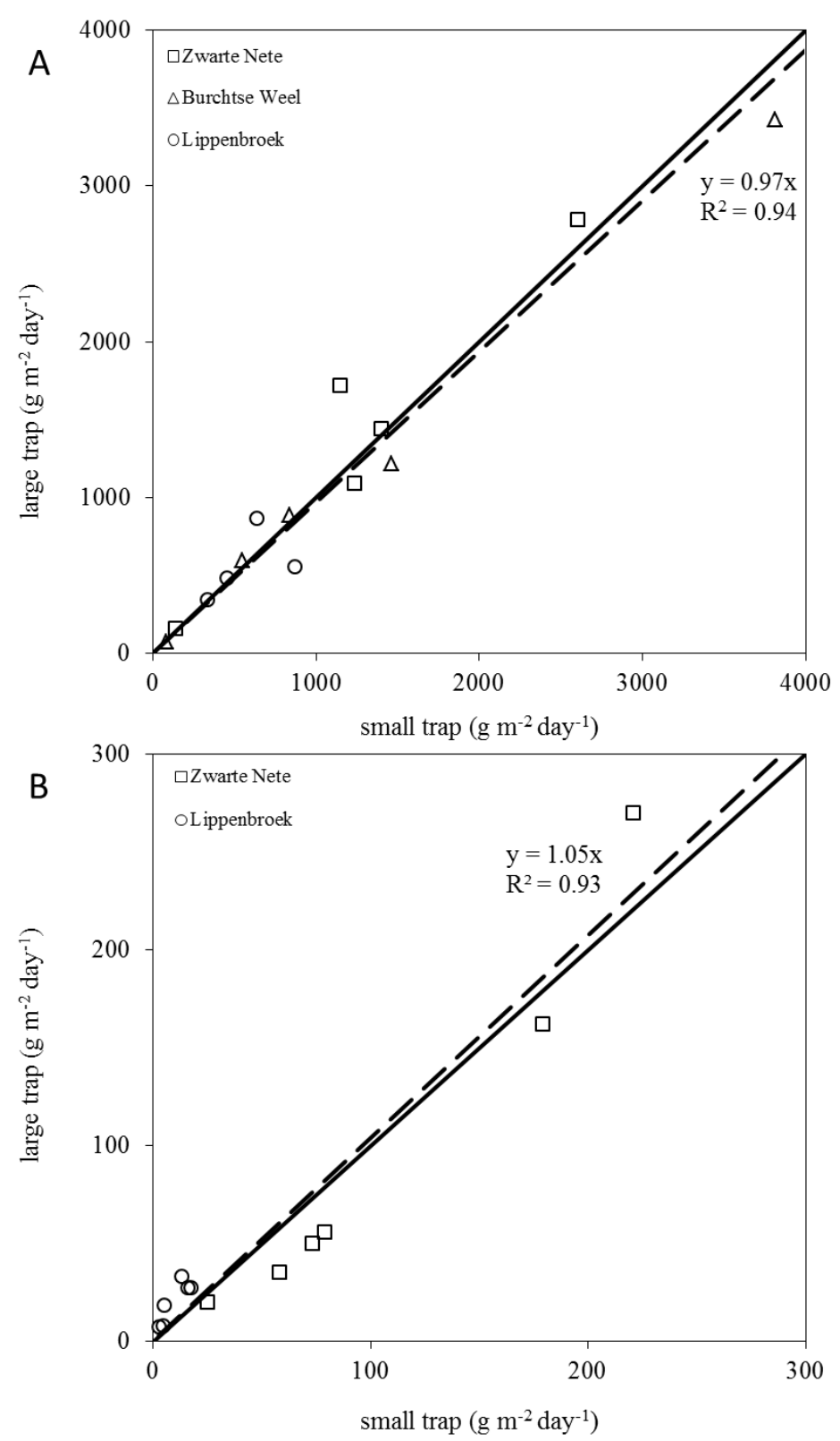

$481 \quad$ Figure 3

482 Linear relations between sedimentation rates derived from small trap data and large trap data 483 over three different ecosystems with bare soil (A), and over two different ecosystems with 484 vegetation (B). Data are significantly correlated (Pearson correlation test, $\mathrm{p}<0.0001$ in both 485 panels) and the linear regressions are represented by a dashed line. A 1:1 relation is represented 486 by a solid line. 


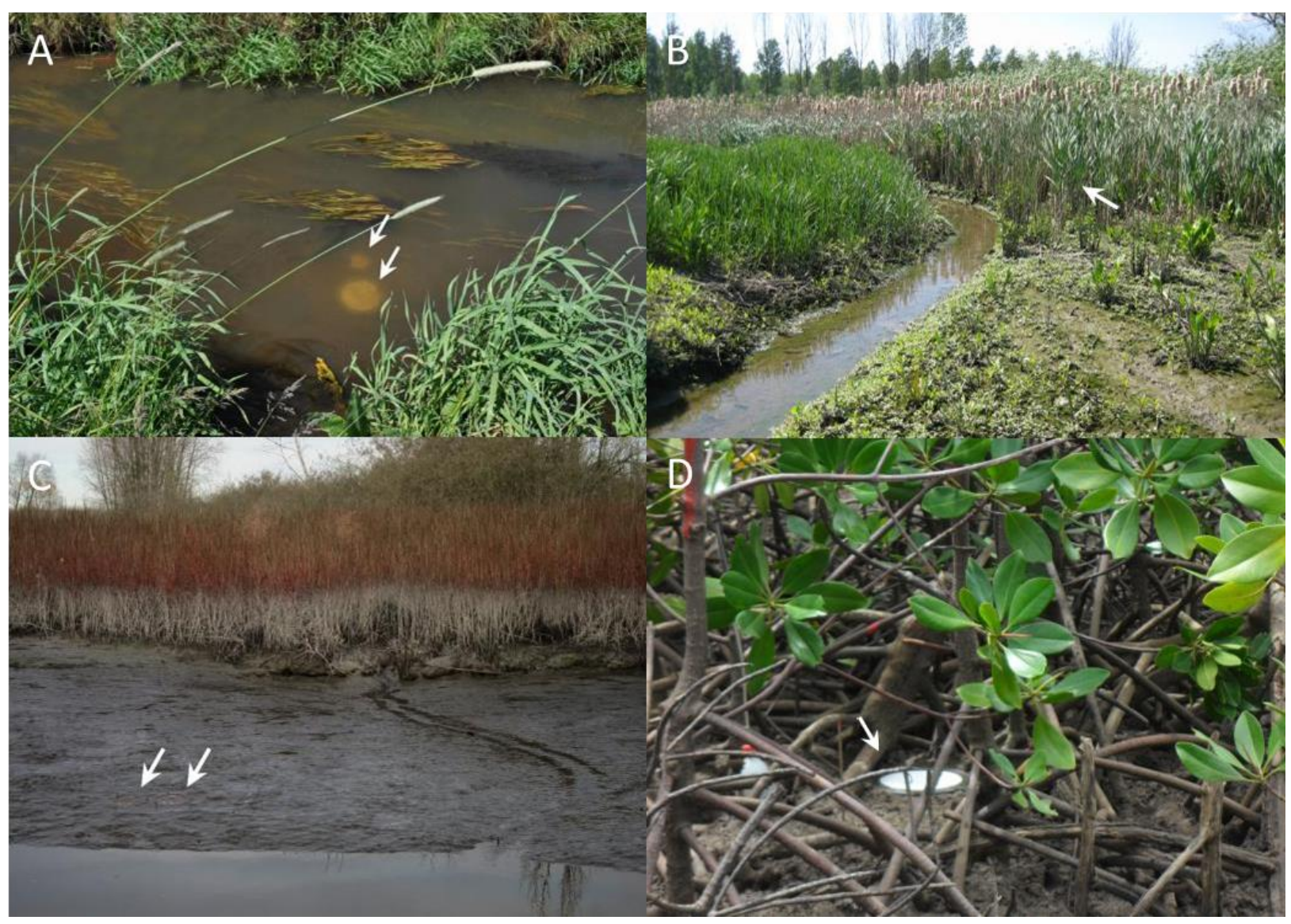

\section{$488 \quad$ Figure 4}

489 These sediment traps may be used in many aquatic ecosystems: (A) in a river with submerged

490 macrophytesas well as in adjacent non-vegetated areas (Zwarte Nete, Belgium); (B) in emergent

491 vegetation on tidal marshes (Lippenbroek polder, Belgium); (C) on non-vegetated mudflats

492 (Lippenbroek polder, Belgium), and (D) between the roots of mangrove trees (Mwache Creek,

493 Kenya). The examples in pictures $\mathrm{A}$ to $\mathrm{C}$ are taken from the previous described field sites.

494 Picture D is an example from a study on sedimentation in response to sea level rise in mangroves

495 (Kimeli, 2013). The position of the traps is indicated with white arrows. 